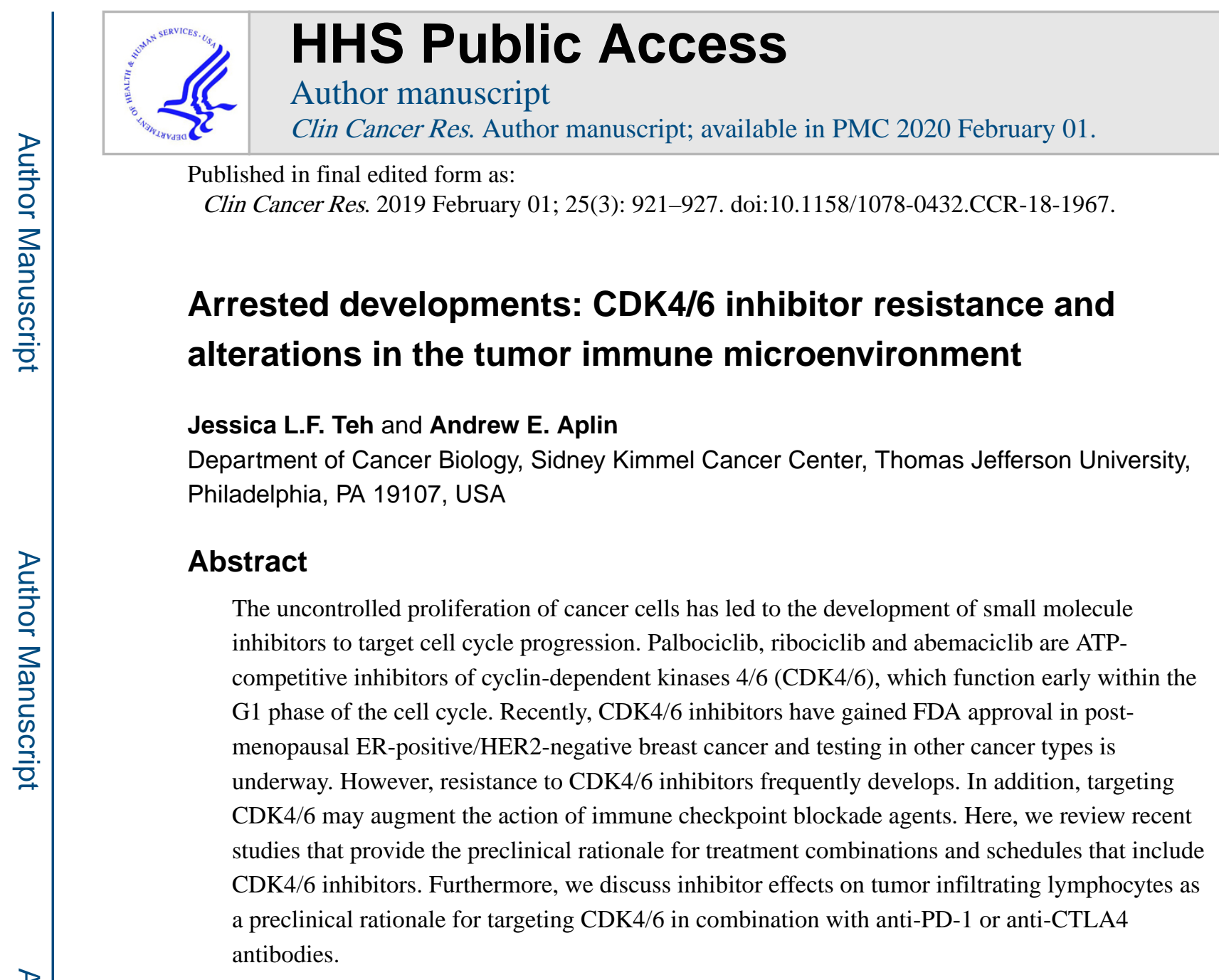

Keywords

Palbociclib; ribociclib; abemaciclib; drug resistance; immune checkpoint inhibitors

\title{
Introduction
}

Deregulated cell cycle progression is a hallmark feature of cancer cells. The cyclindependent kinases, CDK4 and CDK6 (CDK4/6), govern progression through the early G1 phases of the cell cycle. CDK4/6 are positively regulated by association with cyclins D1/D2/D3 (1) and negatively regulated by tumor suppressors, such as p16INK4A encoded by $C D K N 2 A$, that prevents CDK4/6 interaction with D-type cyclins. In response to stimulatory mitogens, cyclin D-CDK4/6 complexes hyper-phosphorylate retinoblastoma protein $(\mathrm{RB})$, thereby uncoupling the latter from E2F transcription factors. Release from RB allows for E2F-driven transcription of genes important for cell cycle progression. Due to the critical roles both p16INK4A and RB play in regulating cell proliferation, inactivating mutations and deletions in the genes encoding these regulators are frequent across many

Corresponding author: Andrew E. Aplin, Department of Cancer Biology, Sidney Kimmel Cancer Center, Thomas Jefferson University, 233 South 10th Street, Philadelphia, PA 19107. Tel: (215) 503-7296. Fax: (215) 923-9248; Andrew.Aplin@ Jefferson.edu. Conflict of interest: A. E. Aplin reports receiving other commercial research support from a Melanoma Research Alliance/Pfizer Inc. Partnership Award. J.L.F. Teh and A. E. Aplin are listed as co-inventors on a patent on E2F reporter cells (US Patent 9,880,150). No other potential conflicts of interest were disclosed. 
tumor types (2-4). In addition to RB, CDK4/6 also phosphorylates FOXM1, NFAT4 and SMAD3 (5-7).

Attempts to target the cell cycle began in the early 1990s with broad targeting CDK inhibitors, flavopiridol (8) and dinaciclib $(9,10)$. However, results from clinical trials were disappointing due to issues concerning low specificity and poorly informed patient selection. Efforts to synthesize more selective CDK inhibitory compounds resulted in the development of the orally available CDK4/6 inhibitor, PD0332991/palbociclib from Pfizer (11). Palbociclib entered clinical trials and received breakthrough therapy designation in May 2015 and subsequent FDA approval for estrogen receptor (ER)-positive, HER2-negative post-menopausal breast cancer patients in combination with an aromatase inhibitor or the selective ER degrader, fulvestrant (11). Additional selective inhibitors of CDK4/6, LEE011/ ribociclib (Novartis) and LY2835219/abemaciclib (Eli-Lily), have been developed with slightly different properties in terms of their dosing and known toxicities in clinical applications (Figure 1). More recently, G1T28/trilaciclib (G1 Therapeutics), a short-acting, intravenously-administered CDK4/6 inhibitor was developed specifically to preserve hematopoietic stem cells from DNA damaging agents such as those widely utilized in chemotherapy $(12,13)$.

Early phase clinical trials of palbociclib, ribociclib and abemaciclib demonstrated superior progression free survival in hormonal therapy combinations (14). In concordance with preclinical data, ER positivity is currently the only marker to predict response to CDK4/6 inhibitor in breast cancer patients (15). The correlation between ER and response in the clinic is intriguing and should be further explored especially in other cancer types. Other intuitive biomarkers for patient selection such as p16INK4A loss and cyclin D1 amplification have not accurately predicted clinical outcomes suggesting that more reliable markers of response are required (14). A large cell line panel screen recently identified cancer cells with D-cyclin activating features (DCAF) but not CDKN2A loss as determinants of response to abemaciclib inhibition (16). These features include ubiquitin ligase FBXO31 loss, cyclin D2/D3 amplification and cyclin D1 3'UTR loss and are frequent events in cancers that have not been extensively explored with CDK4/6 inhibitors. Future trials evaluating patients with DCAF will provide strategies for sensitizing non-responsive tumor (ClinicalTrials.gov: NCT03310879). Nevertheless, the success of CDK4/6 inhibitors in the clinic suggests a requirement for these kinases during breast cancer development and maintenance that may be relevant to the treatment of other cancer types.

\section{Mechanisms of acquired resistance}

CDK4/6 inhibitors delay tumor progression, at least in part, by arresting cells in the G1 phase of the cell cycle and inducing senescence. While the use of CDK4/6 inhibitors in breast cancer is relatively advanced, it is becoming clear that clinical resistance frequently occurs in treated patients (17). Thus, tumor cells can acquire the ability to escape CDK4/6 inhibitor action. Understanding potential mechanisms of acquired resistance to CDK4/6 inhibitors can be broadly categorized as: (i) increased activity of the target e.g. CDK6; (ii) hyper-activation of downstream kinases such as CDK2; and (iii) activation of alternate pathways including mammalian target of rapamycin (mTOR) signaling (Figure 2). 
Importantly, studying mechanisms of resistance to CDK4/6 inhibitors in preclinical models requires validation in patient samples.

Alterations in the cell cycle machinery including CDK6 amplification, cyclin E1 amplification and RB1 loss have been identified in multiple tumor types including breast and ovarian cancer cell lines (18-20). Both amplification events bypass the dependency on cyclin D1-CDK4 signaling, while RB1 loss provides intrinsic resistance to CDK4/6 inhibitors in preclinical studies (21). Overexpression of CDK6 or cyclin E1 were sufficient to confer resistance to CDK4/6 inhibitors in vitro; however, it is unclear how frequent these amplification events occur in patient samples. Pre-clinical evidence in pancreatic ductal adenocarcinoma also points to metabolic functions tied to the cell cycle. Franco and colleagues showed that CDK4/6 inhibition lead to the accumulation of ATP and mitochondria and also stimulated glycolytic and oxidative metabolism associated with mTORC1 activity (22). Metabolic reprogramming of cancer cells by CDK4/6 inhibitors has significant implications since cells may be primed for division after cessation of treatment. Additionally, reactive oxygen species generated by increased metabolic activity and mitochondrial malfunction may contribute to aberrant mutations and autophagy, a stress tolerance mechanism (23).

Other studies have linked by-pass pathways and mTOR signaling to acquired resistance to CDK4/6 inhibitors. In one study, the regulator of AGC kinases, 3-phosphoinositidedependent protein kinase 1/PDK1, and phosphorylation of ribosomal protein S6 (RPS6) were shown to be upregulated by short term treatment of breast cancer ex vivo explants and patient samples (24). CDK4/6 blockade or depletion of cyclin D also increased mTORC2mediated AKT activity in cancer cell lines (25). Mechanistically, Zhang and colleagues demonstrated that inactive/hyper-phosphorylated RB restrains mTORC 2 activity by interacting with Sin1, a component of the mTORC2 complex. Both studies highlight not only E2F-independent functions of RB but also the potential benefits of combining CDK4/6 inhibitor with AKT inhibitors in the RB-proficient setting.

Two complementary translational studies identified genetic mutations and aberrations associated with resistance to CDK4/6 inhibitors in cutaneous melanoma patients. The first study analyzed longitudinal biopsies of a mutant NRAS patient and identified a PI3KCA E545K mutation associated with tumor progression on a MEK inhibitor and CDK4/6 inhibitor combination (26). Interestingly, multi-region analysis of the pre-treated tumor uncovered a low frequency and non-uniform distribution of the PI3KCA E545K mutation suggesting that a pre-existing resistant population had expanded following treatment. In a parallel collaborative study, our group identified NRAS amplification in mutant NRAS cutaneous melanoma in xenograft models and NRAS Q61H/L mutations in mutant BRAF melanomas patient samples treated with CDK4/6 inhibitor-BRAF pathway inhibitor combinations (27). Functional validation showed acquired PIK3CA E545K and NRAS Q61 mutations were sufficient to confer drug resistance (27). Thus, despite different mechanisms, activation of the mTOR-S6K-S6 pathway appears to be a common node of resistance to CDK4/6 inhibitor-based combinations. Furthermore, activation of the S6 pathway may reveal a therapeutic vulnerability since inhibition of S6K or mTORC1/2 re-sensitized resistant cells to a MEK inhibitor plus CDK4/6 inhibitor combination. 
Overall, the current understanding of determinants of response and resistance to CDK4/6 inhibitors points to heterogeneous mechanisms linked to common targetable common nodes. Moving forward, further biopsy sampling of pre-, on- and progression samples will uncover a more detailed repertoire of resistance mechanisms. Analysis of patient-matched circulating tumor DNA from the PALOMA 3 phase III trial has uncovered RB1 mutations in a minority of patients that may be associated with CDK4/6 inhibitor resistance (28). Such findings will inform salvage therapeutic options in resistant patients; however, further studies are required to optimize doses and schedules to offset toxicities. For example, it is unclear whether mTOR inhibitors have negative effects on the immune system since these inhibitors have historically been utilized for prevention of transplant rejection.

\section{Requirement of CDKs/cyclins for immune cell function}

Immune checkpoint inhibitors are the standard of care in some cancer types and are being evaluated in others; thus, an important question surrounding the use of targeted therapies is whether these agents may positively or negatively affect immune cells. In mice, CDK4 knockout leads to insulin-dependent diabetes and female mice are sterile due to abnormal development of pancreatic $\beta$-islet cells and pituitary lactotrophs, respectively (29). By contrast, when CDK6 is disrupted, mice develop thymic and splenic hypoplasia with effects on hematopoietic function $(30,31)$. These findings likely explain why abemaciclib, which is more selective for CDK4 compared to CDK6, can be dosed continuously without adverse events resulting in myelosuppression. Combined knockout of CDK4 and CDK6 in mice leads to late embryonic lethality due to impaired erythroid proliferation (32) indicating that prolonged inhibition of both kinases may not be well tolerated.

The cyclin binding partners of CDK4 or CDK6 have also been implicated in immune cell roles. Cyclin D2 is required for B lymphocyte proliferation while cyclin D3 is important for early B and T cell differentiation and granulocyte proliferation (33,34). Downstream of CDK4/6 in the cell cycle, CDK2 negatively regulates forkhead box P3 (FOXP3), a transcription factor required for the development of regulatory T cells (Tregs) (35) and cyclin A is essential for the proliferation of hematopoietic and embryonic stem cells (36). Given the strong evidence that suggests CDK6 and its cyclin partners play critical roles in regulating hematopoiesis, it is imperative for future clinical trials to monitor the effects of CDK4/6 inhibition on immune cell populations and function. Particularly, development of next generation CDK inhibitors that may target CDK2, as well as CDK4/6 to circumvent cyclin $\mathrm{E}$ amplification will require close monitoring for effects on the immuno-suppressive function of Tregs.

\section{Effects of CDK4/6 inhibition on the tumor immune microenvironment}

There is increasing awareness of the role of non-malignant cells in the tumor microenvironment in regulating tumor response to therapies. Particular attention has focused on the infiltration and activation of different $\mathrm{T}$ cell populations, tumor-associated macrophages and myeloid-derived suppressor cells that may be associated with the durable responses observed with antibodies targeting immune checkpoints in multiple cancer types (reviewed in (37)). Anti-cytotoxic T lymphocyte-associated protein 4 (anti-CTLA4) and 
anti-program cell death 1 (anti-PD-1) antibodies release independent negative checkpoints on immune cells, an action that has been linked to the presence of $\mathrm{T}$ cells within the tumor. Recent studies have indicated that, in addition to serving a direct effect on the tumor, CDK4/6 inhibitors may influence cells in the tumor immune microenvironment. These actions can be categorized into regulation of tumor-secreted cytokines, PD-L1, MHC-1 and $\mathrm{T}$ cell activity (Figure 3 ).

\section{Regulation of tumor-secreted cytokines}

A recognized feature of CDK4/6 inhibitor treatment is the induction of cellular senescence. Senescent cells are metabolically active and they still produce pro-inflammatory cytokines and pro-migratory factors, collectively termed the senescence-associated secretory phenotype (SASP) (38). Therefore, it is possible that CDK4/6 inhibitors may enhance immune cell infiltration through SASP. Utilizing cytokine array analysis of conditioned media from palbociclib-treated melanoma cells, Vilgelm and colleagues observed upregulation of chemokine (C-C motif) ligand 5 (CCL5) (39). CCL5, also known as RANTES (Regulated upon Activation, Normal T Cell Expressed and Secreted) is an inflammatory chemokine ligand for CCR3, CCR5 and CCR1 and is thought to favor T cell infiltration (40); although other studies have shown CCL5 to be involved in immune-evasion (41). Mechanistically, the IKK-NFKB pathway mediates induction of CCL5 in palbociclibtreated cells. TCGA analysis of melanoma showed a strong correlation between CCL5 and T-cell markers (CD2, CD3, CD8A, CXCR3 and CCR5) and cytotoxic immune cells (granzymes and FAS ligand). These findings indicate that CDK4/6 inhibitor-induced senescence may enhance production of a functional chemoattractant for T cells. This idea raises the possibility of utilizing CDK4/6 inhibitors as a priming approach to attract $\mathrm{T}$ cells into cold, $\mathrm{T}$ cell-excluded tumors since pre-existing local CD8+ T cell infiltrates in tumors are more likely to respond to anti-PD-1 (42).

\section{Regulation of T cell activity}

One mechanism of acquired resistance to immunotherapy is the loss of $\mathrm{T}$ cell cytotoxic function (43). Small molecule inhibitors that enhance/maintain the activation status of T cells may be used in combination to potentially enhance effects of immune checkpoint agents. To this end, Deng et al. screened for compounds that may enhance $\mathrm{T}$ cell activity utilizing IL-2 secretion as a readout (7). Interestingly, palbociclib and trilaciclib induced IL-2 in immortalized, PD-1 over-expressing human T cells (Jurkat) in an NFAT-dependent manner. Additionally, palbociclib and trilaciclib increased the secretion of Type 1 T-helper (TH1) cytokines; CXCL9, CXCL10, IFN $\gamma$, IL16, and CXCL16 in patient-derived organotypic tumor spheroids, which contain autologous tumor-infiltrating immune cells. In genetically engineered mouse models of non-small cell lung cancer, palbociclib and trilaciclib enhanced the proportion of CD4+ and CD8+ T cells within tumors. CDK4/6 inhibition also decreased the proportion of immunosuppressive CD11 c+ myeloid cells in tumors, an effect associated with decreased production of IL6, IL10 and IL23. Finally, combination treatment of CDK4/6 inhibitor and PD-1 blockade led to enhanced tumor inhibition which was highly dependent on both CD4+ and CD8+ T cells. Thus, CDK4/6 
inhibition de-represses NFAT to alter cytokine production and increase the trafficking and activation of effector $\mathrm{T}$ cells.

In a distinct study, Goel et al. proposed two mechanisms by which abemaciclib may overcome tumor immune evasion (44). Within tumor cells itself, CDK4/6 inhibition increased endogenous retroviral gene/double stranded RNA response via inhibition of an E2F-target, DNA methyltransferase 1. Ultimately, this effect led to enhanced type III interferon (IFN- $\lambda$ ) production which typically activates STAT1/2 signaling to induce IFNstimulated genes which exert numerous antiviral effector functions (45). Additionally, CDK4/6 inhibitors decreased several immunosuppressive mechanisms within the tumor immune microenvironment. The authors observed a marked decrease in CD4+ FOXP3+ regulatory $\mathrm{T}$ cells (Tregs) not only within the tumor periphery but also in the circulation. The proliferation of CD8+ T cells was unaffected, possibly due to higher CDK6 expression in Tregs compared to other T cell subtypes (46). T cell exhaustion markers such as PD-1, Tim-3, CTLA-4 and LAG3 were also decreased within CD8+ T cells. In a pre-clinical model of mammary carcinoma, 12 day treatment with abemaciclib led to modest tumor regressions that were dependent upon CD8+ cytotoxic T cells. However, the combination of abemaciclib with anti-PDL1 blockade led to more durable responses.

These studies demonstrate two distinct effects of CDK4/6 inhibition on anti-tumor immunity that have important implications for its successful combination with immunotherapy. First, CDK4/6 inhibitors may modulate $\mathrm{T}$ cell activation and downregulate immunosuppressive populations such as Tregs and myeloid populations. Second, CDK4/6 inhibitors mediate increased tumor immunogenicity that allows for enhanced recognition and removal by cytotoxic T lymphocytes. Overall, these findings illustrate that CDK4/6 inhibitors may elicit effects on non-tumor cells within the microenvironment to enhance immune responses.

\section{Regulation of PD-L1}

One factor linked to the response to anti-PD1 checkpoint agents is the expression of PD-L1 on tumor cells; hence, understanding of mechanisms of PD-L1 regulation are paramount. Important for the possible combination of CDK4/6 inhibitor with immunotherapies, Zhang et. al. uncovered a potential link between CDK4/6 activity and PD-L1 protein stability (47). PD-L1 expression fluctuated during the cell cycle and depletion/inhibition of cyclin D and CDK4 increased levels of PD-L1 in breast cancer cells regardless of RB expression. These data were validated in vivo in MMTV-ErbB2 breast cancer, syngeneic colon cancer and melanoma models with corresponding decreases in CD3-positive $\mathrm{T}$ cell populations. These findings offer a rationale for the addition of CDK4/6 inhibitor to improve responses to antiPD-1/PD-L1 therapy. Indeed, the authors showed improved survival outcomes in vivo in two colorectal cancer models. Regulation of PD-L1 occurred via SPOP, a substrate-recruiting adaptor protein of the E3 ligase, cullin 3 which physically interacts with PD-L1. Proof-ofconcept studies show that either knockdown of SPOP or SPOP mutants that ablate substrate interaction led to stabilization of PD-L1, which further correlated with decreased CD3+ immune infiltrates. While SPOP mutations are infrequent events in many cancer types, they have been detected in approximately $10-15 \%$ of human prostate cancers. It would be interesting to determine whether SPOP mutations are associated with response to anti- 
PD-1/PD-L1 therapy. These findings highlight a tumor intrinsic mechanism whereby CDK4/6 inhibitors may alter the response to immunotherapies.

\section{Combinatorial approaches utilizing CDK4/6 inhibitors}

Combination therapies typically present challenges due to toxicities. As a result, suboptimal doses often have to be utilized which limit drug exposure and activity (48). Palbociclib and ribociclib have similar characteristics in that they both target CDK4 and CDK6 with comparable selectivity (Figure 1). Their toxicity profiles are also similar with neutropenia (low neutrophil count) being the most common adverse event, an effect that is manageable with most palbociclib/ribociclib clinical trials administering a 1 week drug holiday following 2-3 weeks of treatment (49). Although abemaciclib inhibits other kinases such as CDK9 and GSK3, it is more selective for CDK4 versus CDK6 (50), which may be a contributing factor to its anti-tumor activity as a monotherapy although more studies are required to clarify this point (15).

Toxicity and efficacy issues may be overcome with altered sequencing and scheduling. Studies in preclinical in vivo models of breast cancer and colorectal cancer have shown that CDK4/6 inhibitors may enhance the susceptibility of tumors to PD-1/PD-L1 blockade $(44,47)$. Interestingly, Schaer and colleagues observed that phased-in doses of anti-PD-L1 after CDK4/6 inhibitor treatment led to more complete responses (51). This schedule was also more efficacious compared to a sequenced combination of CDK4/6 inhibitor treatment followed by anti-PD-L1 treatment suggesting a synergistic interaction between the drugs. A phased-in option may also allow for better tolerability of full FDA-approved doses of individual drugs; however, the mechanistic basis underlying this synergy should be further explored to better inform future clinical trials.

Based on promising pre-clinical data, clinical trials are currently underway for all three FDA-approved CDK4/6 inhibitors in combination with anti-PD-1/PD-L1 inhibitors plus aromatase inhibitors/selective estrogen-receptor degraders (SERD) in ER+ breast cancer patients (NCT03147287, NCT02778685, NCT03294694). Abemaciclib is currently being investigated in combination with anti-PD-1/PD-L1 in advanced solid tumors (NCT02791334). Since immune cells are reliant on CDKs and cyclins, long term effects of CDK4/6 inhibitors on $\mathrm{T}$ cell propagation should be monitored closely to test for compatibility with immunotherapy. Undesirable impacts on $\mathrm{T}$ cell function might potentially be circumvented by agonist immunotherapy, such as OX-40 and 4-1BB (52).

\section{Conclusions and Future Perspectives}

The clinical efficacy of CDK4/6 inhibitors in subsets of breast cancer have highlighted their potential utilization across many cancer types. However, given the need for their use in combination, the scheduling and/or sequencing of their use should be carefully considered. Pre-clinical in vivo reporter models provide an ideal system to optimize dosing schedules $(27,53)$. The effects of diet may also be considered especially given the preclinical evidence that high fat diets fuel the growth of mutant BRAF melanoma xenografts (54). In this review, we have highlighted strong data in support of CDK4/6 inhibitor use to alter the tumor 
immune microenvironment in a way that may enhance the effects of immuno-oncology agents. In addition, other aspects of the tumor microenvironment may be involved. Endothelial-mediated neovascularization supplies nutrients to growing tumors, adipocytes supply fatty acids for tumor growth and growth factors and extracellular matrix produced by stromal fibroblasts also modulate the growth response to targeted therapies. Furthermore, recent evidence has shown that diversity of the gut microbiome is associated with immune checkpoint responses (55-57). The effect of targeted therapies on the gut bacterial flora may therefore need to be explored. These and other emerging discoveries underscore the possibilities of future exciting developments for cell cycle inhibitors in cancer.

\section{Acknowledgments}

Financial Support: This work is supported by grants from NIH/NCI (CA182635 and CA160495 to A.E.A.), Rochester Melanoma Action Group/Outrun the Sun Melanoma Research Scholar Award (to J.L.F. Teh), and an AACR-Ocular Melanoma Foundation Fellowship (to J.L.F. Teh).

\section{References}

1. Sherr CJ. Cancer cell cycles. Science 1996;274:1672-7. [PubMed: 8939849]

2. Young RJ, Waldeck K, Martin C, Foo JH, Cameron DP, Kirby L, et al. Loss of CDKN2A expression is a frequent event in primary invasive melanoma and correlates with sensitivity to the CDK4/6 inhibitor PD0332991 in melanoma cell lines. Pigment Cell Melanoma Res 2014;27:590-600. [PubMed: 24495407]

3. Schutte M, Hruban RH, Geradts J, Maynard R, Hilgers W, Rabindran SK, et al. Abrogation of the $\mathrm{Rb} / \mathrm{p} 16$ tumor-suppressive pathway in virtually all pancreatic carcinomas. Cancer Res 1997;57:3126-30. [PubMed: 9242437]

4. Classon M, Harlow E. The retinoblastoma tumour suppressor in development and cancer. Nat Rev Cancer 2002;2:910-7. [PubMed: 12459729]

5. Anders L, Ke N, Hydbring P, Choi YJ, Widlund HR, Chick JM, et al. A systematic screen for CDK4/6 substrates links FOXM1 phosphorylation to senescence suppression in cancer cells. Cancer Cell 2011;20:620-34. [PubMed: 22094256]

6. Matsuura I, Denissova NG, Wang G, He D, Long J, Liu F. Cyclin-dependent kinases regulate the antiproliferative function of Smads. Nature 2004;430:226-31. [PubMed: 15241418]

7. Deng J, Wang ES, Jenkins RW, Li S, Dries R, Yates K, et al. CDK4/6 Inhibition Augments Antitumor Immunity by Enhancing T-cell Activation. Cancer Discov 2018;8:216-33. [PubMed: 29101163]

8. Kaur G, Stetler-Stevenson M, Sebers S, Worland P, Sedlacek H, Myers C, et al. Growth inhibition with reversible cell cycle arrest of carcinoma cells by flavone L86-8275. J Natl Cancer Inst 1992;84:1736-40. [PubMed: 1279187]

9. Paruch K, Dwyer MP, Alvarez C, Brown C, Chan TY, Doll RJ, et al. Discovery of Dinaciclib (SCH 727965): A Potent and Selective Inhibitor of Cyclin-Dependent Kinases. ACS Med Chem Lett 2010;1:204-8. [PubMed: 24900195]

10. Parry D, Guzi T, Shanahan F, Davis N, Prabhavalkar D, Wiswell D, et al. Dinaciclib (SCH 727965), a novel and potent cyclin-dependent kinase inhibitor. Mol Cancer Ther 2010;9:2344-53. [PubMed: 20663931]

11. Fry DW, Harvey PJ, Keller PR, Elliott WL, Meade M, Trachet E, et al. Specific inhibition of cyclin-dependent kinase 4/6 by PD 0332991 and associated antitumor activity in human tumor xenografts. Mol Cancer Ther 2004;3:1427-38. [PubMed: 15542782]

12. Bisi JE, Sorrentino JA, Roberts PJ, Tavares FX, Strum JC. Preclinical Characterization of G1T28: A Novel CDK4/6 Inhibitor for Reduction of Chemotherapy-Induced Myelosuppression. Mol Cancer Ther 2016;15:783-93. [PubMed: 26826116] 
13. He S, Roberts PJ, Sorrentino JA, Bisi JE, Storrie-White H, Tiessen RG, et al. Transient CDK4/6 inhibition protects hematopoietic stem cells from chemotherapy-induced exhaustion. Sci Transl Med 2017;9.

14. Finn RS, Crown JP, Lang I, Boer K, Bondarenko IM, Kulyk SO, et al. The cyclin-dependent kinase 4/6 inhibitor palbociclib in combination with letrozole versus letrozole alone as first-line treatment of oestrogen receptor-positive, HER2-negative, advanced breast cancer (PALOMA-1/TRIO-18): a randomised phase 2 study. Lancet Oncol 2015;16:25-35. [PubMed: 25524798]

15. Patnaik A, Rosen LS, Tolaney SM, Tolcher AW, Goldman JW, Gandhi L, et al. Efficacy and Safety of Abemaciclib, an Inhibitor of CDK4 and CDK6, for Patients with Breast Cancer, Non-Small Cell Lung Cancer, and Other Solid Tumors. Cancer Discov 2016;6:740-53. [PubMed: 27217383]

16. Gong X, Litchfield LM, Webster Y, Chio LC, Wong SS, Stewart TR, et al. Genomic Aberrations that Activate D-type Cyclins Are Associated with Enhanced Sensitivity to the CDK4 and CDK6 Inhibitor Abemaciclib. Cancer Cell 2017;32:761-76 e6. [PubMed: 29232554]

17. Finn RS, Martin M, Rugo HS, Jones S, Im SA, Gelmon K, et al. Palbociclib and Letrozole in Advanced Breast Cancer. N Engl J Med 2016;375:1925-36. [PubMed: 27959613]

18. Yang C, Li Z, Bhatt T, Dickler M, Giri D, Scaltriti M, et al. Acquired CDK6 amplification promotes breast cancer resistance to CDK4/6 inhibitors and loss of ER signaling and dependence. Oncogene 2017;36:2255-64. [PubMed: 27748766]

19. Herrera-Abreu MT, Palafox M, Asghar U, Rivas MA, Cutts RJ, Garcia-Murillas I, et al. Early Adaptation and Acquired Resistance to CDK4/6 Inhibition in Estrogen Receptor-Positive Breast Cancer. Cancer Res 2016;76:2301-13. [PubMed: 27020857]

20. Taylor-Harding B, Aspuria PJ, Agadjanian H, Cheon DJ, Mizuno T, Greenberg D, et al. Cyclin E1 and RTK/RAS signaling drive CDK inhibitor resistance via activation of E2F and ETS. Oncotarget 2015;6:696-714. [PubMed: 25557169]

21. Dean JL, McClendon AK, Hickey TE, Butler LM, Tilley WD, Witkiewicz AK, et al. Therapeutic response to CDK4/6 inhibition in breast cancer defined by ex vivo analyses of human tumors. Cell Cycle 2012;11:2756-61. [PubMed: 22767154]

22. Franco J, Balaji U, Freinkman E, Witkiewicz AK, Knudsen ES. Metabolic Reprogramming of Pancreatic Cancer Mediated by CDK4/6 Inhibition Elicits Unique Vulnerabilities. Cell Rep 2016;14:979-90. [PubMed: 26804906]

23. Vijayaraghavan S, Karakas C, Doostan I, Chen X, Bui T, Yi M, et al. CDK4/6 and autophagy inhibitors synergistically induce senescence in $\mathrm{Rb}$ positive cytoplasmic cyclin $\mathrm{E}$ negative cancers. Nat Commun 2017;8:15916. [PubMed: 28653662]

24. Jansen VM, Bhola NE, Bauer JA, Formisano L, Lee KM, Hutchinson KE, et al. Kinome-Wide RNA Interference Screen Reveals a Role for PDK1 in Acquired Resistance to CDK4/6 Inhibition in ER-Positive Breast Cancer. Cancer Res 2017;77:2488-99. [PubMed: 28249908]

25. Zhang J, Xu K, Liu P, Geng Y, Wang B, Gan W, et al. Inhibition of Rb Phosphorylation Leads to mTORC2-Mediated Activation of Akt. Mol Cell 2016;62:929-42. [PubMed: 27237051]

26. Romano G, Chen PL, Song P, McQuade JL, Liang RJ, Liu M, et al. A Preexisting Rare PIK3CA(E545K) Subpopulation Confers Clinical Resistance to MEK plus CDK4/6 Inhibition in NRAS Melanoma and Is Dependent on S6K1 Signaling. Cancer Discov 2018;8:556-67. [PubMed: 29496665]

27. Teh JLF, Cheng PF, Purwin TJ, Nikbakht N, Patel P, Chervoneva I, et al. In Vivo E2F Reporting Reveals Efficacious Schedules of MEK1/2-CDK4/6 Targeting and mTOR-S6 Resistance Mechanisms. Cancer Discov 2018;8:568-81. [PubMed: 29496664]

28. Turner NC, O'Leary B, Cutts R, Liu Y, Hrebien S, Huang X, et al. Genetic landscape of resistance to CDK4/6 inhibition in circulating tumor DNA (ctDNA) analysis of the PALOMA3 trial of palbociclib and fulvestrant versus placebo and fulvestrant. J Clin Oncol 2018;38:suppl; abstr 1001.

29. Rane SG, Dubus P, Mettus RV, Galbreath EJ, Boden G, Reddy EP, et al. Loss of Cdk4 expression causes insulin-deficient diabetes and Cdk4 activation results in beta-islet cell hyperplasia. Nat Genet 1999;22:44-52. [PubMed: 10319860]

30. Hu MG, Deshpande A, Enos M, Mao D, Hinds EA, Hu GF, et al. A requirement for cyclindependent kinase 6 in thymocyte development and tumorigenesis. Cancer Res 2009;69:810-8. [PubMed: 19155308] 
31. Hu MG, Deshpande A, Schlichting N, Hinds EA, Mao C, Dose M, et al. CDK6 kinase activity is required for thymocyte development. Blood 2011;117:6120-31. [PubMed: 21508411]

32. Malumbres M, Sotillo R, Santamaria D, Galan J, Cerezo A, Ortega S, et al. Mammalian cells cycle without the D-type cyclin-dependent kinases Cdk4 and Cdk6. Cell 2004;118:493-504. [PubMed: 15315761]

33. Sicinska E, Aifantis I, Le Cam L, Swat W, Borowski C, Yu Q, et al. Requirement for cyclin D3 in lymphocyte development and T cell leukemias. Cancer Cell 2003;4:451-61. [PubMed: 14706337]

34. Cooper AB, Sawai CM, Sicinska E, Powers SE, Sicinski P, Clark MR, et al. A unique function for cyclin D3 in early B cell development. Nat Immunol 2006;7:489-97. [PubMed: 16582912]

35. Chunder N, Wang L, Chen C, Hancock WW, Wells AD. Cyclin-dependent kinase 2 controls peripheral immune tolerance. J Immunol 2012;189:5659-66. [PubMed: 23136201]

36. Kalaszczynska I, Geng Y, Iino T, Mizuno S, Choi Y, Kondratiuk I, et al. Cyclin A is redundant in fibroblasts but essential in hematopoietic and embryonic stem cells. Cell 2009;138:352-65. [PubMed: 19592082]

37. Balkwill FR, Capasso M, Hagemann T. The tumor microenvironment at a glance. J Cell Sci 2012;125:5591-6. [PubMed: 23420197]

38. Coppe JP, Desprez PY, Krtolica A, Campisi J. The senescence-associated secretory phenotype: the dark side of tumor suppression. Annu Rev Pathol 2010;5:99-118. [PubMed: 20078217]

39. Vilgelm AE, Johnson CA, Prasad N, Yang J, Chen SC, Ayers GD, et al. Connecting the Dots: Therapy-Induced Senescence and a Tumor-Suppressive Immune Microenvironment. J Natl Cancer Inst 2016;108:djv406.

40. Hong M, Puaux AL, Huang C, Loumagne L, Tow C, Mackay C, et al. Chemotherapy induces intratumoral expression of chemokines in cutaneous melanoma, favoring T-cell infiltration and tumor control. Cancer Res 2011;71:6997-7009. [PubMed: 21948969]

41. Wang X, Lang M, Zhao T, Feng X, Zheng C, Huang C, et al. Cancer-FOXP3 directly activated CCL5 to recruit FOXP3(+)Treg cells in pancreatic ductal adenocarcinoma. Oncogene 2017;36:3048-58. [PubMed: 27991933]

42. Tumeh PC, Harview CL, Yearley JH, Shintaku IP, Taylor EJ, Robert L, et al. PD-1 blockade induces responses by inhibiting adaptive immune resistance. Nature 2014;515:568-71. [PubMed: 25428505]

43. Sharma P, Hu-Lieskovan S, Wargo JA, Ribas A. Primary, Adaptive, and Acquired Resistance to Cancer Immunotherapy. Cell 2017;168:707-23. [PubMed: 28187290]

44. Goel S, DeCristo MJ, Watt AC, BrinJones H, Sceneay J, Li BB, et al. CDK4/6 inhibition triggers anti-tumour immunity. Nature 2017;548:471-5. [PubMed: 28813415]

45. Syedbasha M, Egli A. Interferon Lambda: Modulating Immunity in Infectious Diseases. Front Immunol 2017;8:119. [PubMed: 28293236]

46. De Simone M, Arrigoni A, Rossetti G, Gruarin P, Ranzani V, Politano C, et al. Transcriptional Landscape of Human Tissue Lymphocytes Unveils Uniqueness of Tumor-Infiltrating T Regulatory Cells. Immunity 2016;45:1135-47. [PubMed: 27851914]

47. Zhang J, Bu X, Wang H, Zhu Y, Geng Y, Nihira NT, et al. Cyclin D-CDK4 kinase destabilizes PDL1 via cullin 3-SPOP to control cancer immune surveillance. Nature 2018;553:91-5. [PubMed: 29160310]

48. Ascierto PA, Bechter O, Wolter P, Lebbe C, Elez E, Miller WH. A phase Ib/II dose-escalation study evaluating triple combination therapy with a BRAF (encorafenib), MEK (binimetinib), and CDK 4/6 (ribociclib) inhibitor in patients (Pts) with BRAF V600-mutant solid tumors and melanoma. J Clin Oncol 2017;35:Abstract 9518.

49. Tripathy D, Bardia A, Sellers WR. Ribociclib (LEE011): Mechanism of Action and Clinical Impact of This Selective Cyclin-Dependent Kinase 4/6 Inhibitor in Various Solid Tumors. Clin Cancer Res 2017;23:3251-62. [PubMed: 28351928]

50. Cousins EM, Goldfarb D, Yan F, Roques J, Darr D, Johnson GL, et al. Competitive Kinase Enrichment Proteomics Reveals that Abemaciclib Inhibits GSK3beta and Activates WNT Signaling. Mol Cancer Res 2018;16:333-44. [PubMed: 29133594] 
51. Schaer DA, Beckmann RP, Dempsey JA, Huber L, Forest A, Amaladas N, et al. The CDK4/6 Inhibitor Abemaciclib Induces a T Cell Inflamed Tumor Microenvironment and Enhances the Efficacy of PD-L1 Checkpoint Blockade. Cell Rep 2018;22:2978-94. [PubMed: 29539425]

52. Dushyanthen S, Teo ZL, Caramia F, Savas P, Mintoff CP, Virassamy B, et al. Agonist immunotherapy restores $\mathrm{T}$ cell function following MEK inhibition improving efficacy in breast cancer. Nat Commun 2017;8:606. [PubMed: 28928458]

53. Basile KJ, Abel EV, Dadpey N, Hartsough EJ, Fortina P, Aplin AE. In vivo MAPK reporting reveals the heterogeneity in tumoral selection of resistance to RAF inhibitors. Cancer Res 2013;73:7101-10. [PubMed: 24121492]

54. Xia S, Lin R, Jin L, Zhao L, Kang HB, Pan Y, et al. Prevention of Dietary-Fat-Fueled Ketogenesis Attenuates BRAF V600E Tumor Growth. Cell Metab 2017;25:358-73. [PubMed: 28089569]

55. Matson V, Fessler J, Bao R, Chongsuwat T, Zha Y, Alegre ML, et al. The commensal microbiome is associated with anti-PD-1 efficacy in metastatic melanoma patients. Science 2018;359:104-8. [PubMed: 29302014]

56. Gopalakrishnan V, Spencer CN, Nezi L, Reuben A, Andrews MC, Karpinets TV, et al. Gut microbiome modulates response to anti-PD-1 immunotherapy in melanoma patients. Science 2018;359:97-103. [PubMed: 29097493]

57. Routy B, Le Chatelier E, Derosa L, Duong CPM, Alou MT, Daillere R, et al. Gut microbiome influences efficacy of PD-1-based immunotherapy against epithelial tumors. Science 2018;359:917. [PubMed: 29097494] 


\begin{tabular}{|c|c|c|c|c|c|c|}
\hline Inhibitor & $\begin{array}{l}\text { Company } \\
\text { source }\end{array}$ & Structure & Targets & $\begin{array}{l}\text { Dose } \\
\text { per day }\end{array}$ & Major Toxicities & References \\
\hline Palbociclib & Pfizer & $\begin{array}{c}\mathrm{C}_{2} \mathrm{H}_{2} \mathrm{~N}_{2} \mathrm{O}_{2} \\
\mathrm{M}: 447.543\end{array}$ & $\begin{array}{l}\text { CDK4: } 11 \mathrm{nM} \\
\text { CDK6: } 15 \mathrm{nM}\end{array}$ & $\begin{array}{l}125 \mathrm{mg} \text { p.o. } \\
21 \text { days out } \\
\text { of a } 28 \text { day } \\
\text { cycle }\end{array}$ & $\begin{array}{l}\text { Neutropenia } \\
\text { Thrombocytopenia }\end{array}$ & 11,14 \\
\hline Ribociclib & Novartis & $\begin{array}{l}\mathrm{C}_{23} \mathrm{H}_{30} \mathrm{~N}_{8} \mathrm{O} \\
\mathrm{MW}: 434.548\end{array}$ & $\begin{array}{l}\text { CDK4: } 10 \mathrm{nM} \\
\text { CDK6: } 39 \mathrm{nM}\end{array}$ & $\begin{array}{l}600 \mathrm{mg} \text { p.o. } \\
21 \text { days out } \\
\text { of a } 28 \text { day } \\
\text { cycle }\end{array}$ & $\begin{array}{l}\text { Neutropenia } \\
\text { Thrombocytopenia } \\
\text { QT prolongation }\end{array}$ & 48 \\
\hline Abemaciclib & Eli-Lily & $\begin{array}{l}\mathrm{C}_{2} \mathrm{H}_{2} \mathrm{~F}_{2} \mathrm{~N}_{8} \\
\mathrm{MW}: 434.548\end{array}$ & $\begin{array}{l}\text { CDK4: } 0.6-2 \mathrm{nM} \\
\text { CDK6: } 2.4-5 \mathrm{nM} \\
\text { CDK9: } 57 \mathrm{nM}\end{array}$ & $\begin{array}{l}300 \mathrm{mg}- \\
400 \mathrm{mg} \text { p.o. } \\
\text { continuous }\end{array}$ & $\begin{array}{l}\text { Diarrhea } \\
\text { Fatigue }\end{array}$ & 15 \\
\hline Trilaciclib & $\begin{array}{l}\text { G1 } \\
\text { Therapeutics }\end{array}$ & $\begin{array}{l}-\mathrm{Cu} \\
\mathrm{C}_{2 \mathrm{H}_{3} \mathrm{~N}_{2} \mathrm{O}} \\
\text { MW: } 446.559\end{array}$ & $\begin{array}{l}\text { CDK4: } 1 \mathrm{nM} \\
\text { CDK6: } 4 \mathrm{nM} \\
\text { CDK9: } 50 \mathrm{nM}\end{array}$ & $\begin{array}{l}200- \\
240 \mathrm{mg} / \mathrm{m}^{2} \\
\text { intravenous } \\
1-5 \text { days } \\
\text { out of } 21 \\
\text { days }\end{array}$ & Thrombocytopenia & 12 \\
\hline
\end{tabular}

Figure 1. Characteristics of CDK4/6 inhibitors in the clinic.

Chemical structures were retrieved from National Center for Biotechnology Information. 


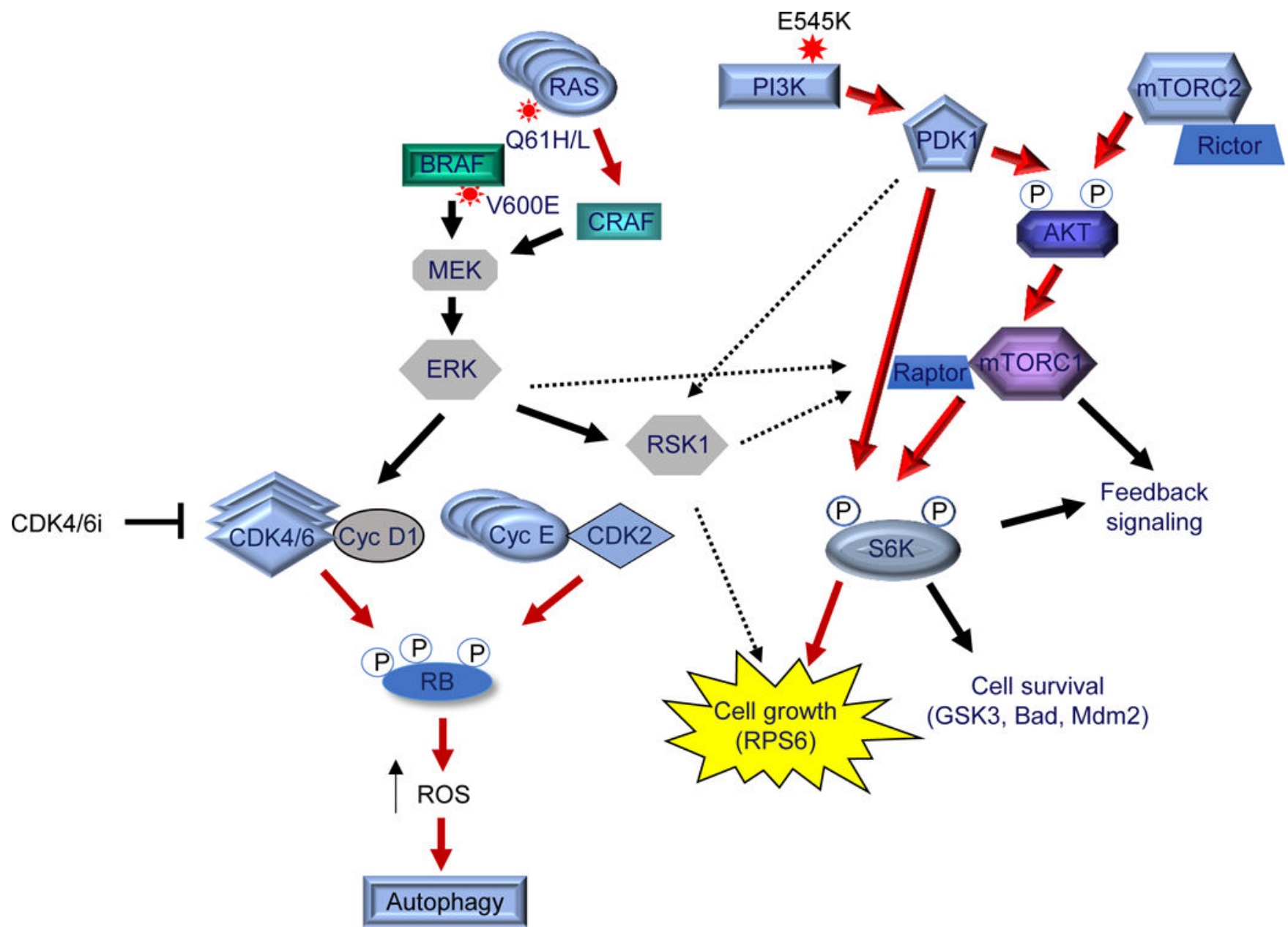

Figure 2. Acquired resistance mechanisms to CDK4/6 targeting.

Multiple resistance mechanisms have been identified and validated in human patient samples. These include two separate NRAS mutations $(\mathrm{Q} 61 \mathrm{H} / \mathrm{L})$ identified in a mutant BRAF melanoma patient and a PI3KCA E545K mutation found in a mutant NRAS melanoma patient. PDK1 expression was also increased in post-palbociclib treated breast cancer patient samples compared to naïve tumors. In a mouse xenograft model, NRAS amplification mediated MEK inhibitor plus CDK4/6 inhibitor resistance. Together, these resistance mechanisms led to upregulation of mTOR-S6 pathway and provided a therapeutic window for mTOR/S6K targeting. In pre-clinical studies, other alterations were identified within cell cycle components, such as CDK6 and cyclin E amplification. Next generation CDK inhibitors are currently in development to concurrently target CDK2 to combat resistance. 


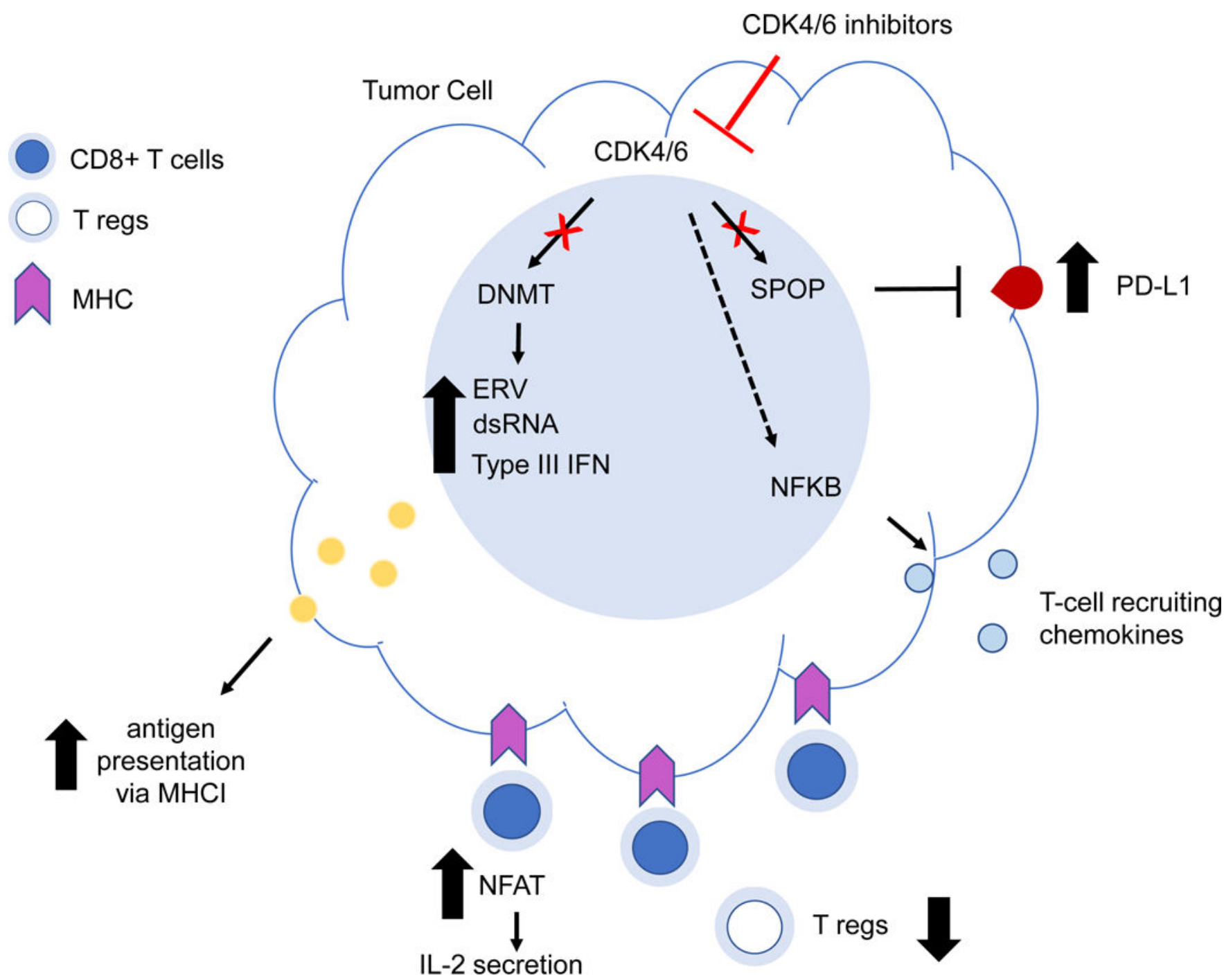

Figure 3. Effects of CDK4/6 inhibition on the tumor immune microenvironment. It is becoming apparent that CDK4/6 inhibitors may not only have tumor-specific functions but could also affect the tumor microenvironment. Within tumor cells, CDK4/6 inhibitors increase expression of PD-L1 through the E3 ligase adapter protein, SPOP and enhance antigen presentation via reduced activity of the E2F target, DNA methyltransferase 1 (DNMT). Secretion of cytokines from both tumor and CD8 positive $\mathrm{T}$ cells is also enhanced with CDK4/6 inhibitor treatment while proliferation of immunosuppressive regulatory $\mathrm{T}$ cells is suppressed. 